\title{
PSYCHE
}

$\begin{array}{lll}\text { Vol. } 75 & \text { June, } 1968 & \text { No. } 2\end{array}$

\section{A NEW CAVE CATOPID BEETLE FROM MEXICO, WITH A DISCUSSION OF ITS EVOLUTION.*}

\author{
By Stewart B. Peck \\ Museum of Comparative Zoology, Harvard University
}

Most obligately cave-inhabiting (troglobitic) beetles belong to the families Carabidae, Catopidae, and Pselaphidae. From Mexico, troglobitic species have been described in the Carabid tribes Trechini and Agonini (Barr 1966a, 1966b, and Bolivar y Peltain and Hendrichs 1964). The family Catopidae contains numerous troglobitic species in several genera in Europe, and several species in the genus Ptomaphagus in the United States (Jeannel 1936, and Barr I963). From Mexico, three species of Ptomaphagus have been recorded; $P$. (Tupania) forticornis Matthews, $P$. (Adelops) inermis Jeannel, and $P$. spelaeus Bilimek (Jeannel 1936, Szymczakowski 1961). The last of these was described from Cacahuamilpa Cave, near Taxco, in the state of Guerrero. It does not possess any structures suggesting that it is limited to a cavernicolous life.

During the past few years, collections of six undescribed Ptomaphagus species from I2 Mexican caves have been sent to me by members of the Association for Mexican Cave Studies for inclusion in a revision of the genus. With the exception of a single female, these species show no structural specializations suggesting that they are limited to caves. However, a collection was recently made in a high altitude cave of a male of a highly modified species. This collection reinforces current ideas on the origin of tropical troglobitic beetles. The new species is described and discussed in this paper.

This paper is the first in a series on the evolution and biology of the Ptomaphagus and other catopid beetles of North America. It includes a departure from the usual method of describing cavernicolous species of Ptomaphagus. One morphological clue to the de-

*Manuscript received by the editor June 6, 1968 
gree of adaptation attained by a cave inhabiting beetle is the degree of lengthening of the body and appendages. Measurements are used extensively here to document these lengths. All measurements are in millimeters and were made with a calibrated ocular micrometer. The antennal segment measurements give maximum widths, and the lengths do not include the basal bulb of articulation.

I thank James Reddell for making this and other collections of Mexican Catopidae available to me for study. I also thank the many members of the Association for Mexican Cave Studies who have helped to collect these beetles. Professor Philip J. Darlington, Jr., kindly reviewed the manuscript.

\section{Ptomaphagus (Adelops) troglomexicanus n. sp.}

Figs. I-5.

Holotype. Known only from a unique male, (deposited in the Museum of Comparative Zoology, Harvard University, MCZ type number 31653), collected in Cueva de la Perra, at an elevation of 2 I60 m (7100 feet), La Perra, I5 miles northwest of Gomez Farias, Tamaulipas, Mexico; 28 January, I968; James Reddell, Robert W. Mitchell, Francis Rose, and John George collectors. Found in cave at base of flowstone slope.

Description. Length $4.0 \mathrm{~mm}$. Width $1.70 \mathrm{~mm}$. Color dark brown. Shape oblong, very convex, narrowing posteriorly (Fig. I). Metathoracic wings absent. Eyes small, diameter o.13; facets present but indistinct (Fig. 2) ; pigment absent. Antennae long and thin, covering first third of elytra when laid back; club composed of last five segments; well supplied with abundant setae and with hairs at ends of segments. Segment measurements, lengths followed by widths; I, 0.34, 0.II ; II, 0.22, 0.08; III, 0.29, 0.065; IV, 0.29, $0.065 ; \mathrm{V}, 0.26,0.065 ; \mathrm{VI}, 0.22$, 0.08 ; VII, 0.22, 0.I I ; VIII, 0.13, 0.09; IX, 0.I8, 0.II; X, 0.I8, 0.I2; XI, 0.25, 0.II. Pronotum maximum width I.66, one third before base; midline length I.I5; hind angles a little less than right, acuminate; front angles broadly rounded; base shallowly emarginate medial to hind angles; disc uniformly covered with short golden pubescense and transverse strigae. Elytra width I.7O, widest a little behind base; length 2.70 ; gradually narrowing in apical two thirds; apex rounded in male (female unknown) ; clothed with dense golden hairs; strigae oblique to suture. Hind tibia length 1.46, width at middle 0.13. Fore tarsi with first three segments swollen in male. Mid tarsi and hind tarsi normal. Hind tarsal segment lengths: I (basal) 0.56 ; II 0.3 I ; III 0.25 ; IV $0.22 ; \mathrm{V} 0.29$; chord of arc of claw 0.13 . Mesosternal carina low and 
uniformly rounded. Aedeagus (Figs. 4, 5) long and thin: in dorsal view sides straight and parallel; in lateral view chord length 1.46 , curved at base, straight in middle, tapering gently to tip; tip slightly acuminate in lateral and ventral views; five hairs on each side of ventral surface; parameres equal, bearing two hairs at ends.

Diagnosis. The species is easily separated from all other Ptomaphagus by the combination of the following characters; the pigmentless but faintly faceted eyes whose maximum width is slightly less than a third the distance from the edge of the antennal socket to the lateral carina of the head, the thin elongate antennae covering the first third of the elytra when laid back, and the shape of the aedeagus.

The abundant long pubescence of troglomexicanus may suggest a relationship to $P$. spelaeus (a Mexican cavernicole) $P$. giaquintoi Jeannel (a Guatemalan cavernicole) and an undescribed Guatemalan cavernicole. However, these last three species are one third smaller in body length. The aedeagus of the third species is as straight but not as thin as in troglomexicanus. The aedeagus has not been figured or described for the other two species.

The species groups of Ptomaphagus. The species described in this paper cannot at this time be placed in the phyletic groups of Ptomaphagus recognized by Jeannel (1949). Parts of his definitions are based upon female characters which are unknown for this species. Secondly, I have found some of Jeannel's species groupings to be polyphyletic assemblages which have convergently reached similar levels of specialization. For instance, Jeannel places in the hirtus group $P$. hirtus Tellkampf (a troglobite from central Kentucky) and $P$. mitchellensis Hatch (a litter inhabitant from the Black Mountains of North Carolina). Both beetles posses similar shapes, but the very unusual aedeagus of mitchellensis demonstrates that it is distant from any other described North American Ptomaphagus. The aedeagus of hirtus indicates a close relation to $P$. nicholasi Barr and $P$. hubrichti Barr. These troglobitic species from Illinois and Tennessee respectively were unknown to Jeannel. I interpret the similarity of these three troglobites to be indicative of descent from a single ancestral species independently colonizing caves in the three states.

In the future, it may prove necessary to recognize a separate species group to contain troglomexicanus and a similar-sized, undescribed species possessing small, pigmentless eyes and short, metathoracic wings. The latter is presently known only from a single female from a gypsum cave in the Mexican state of Nuevo Leon. 

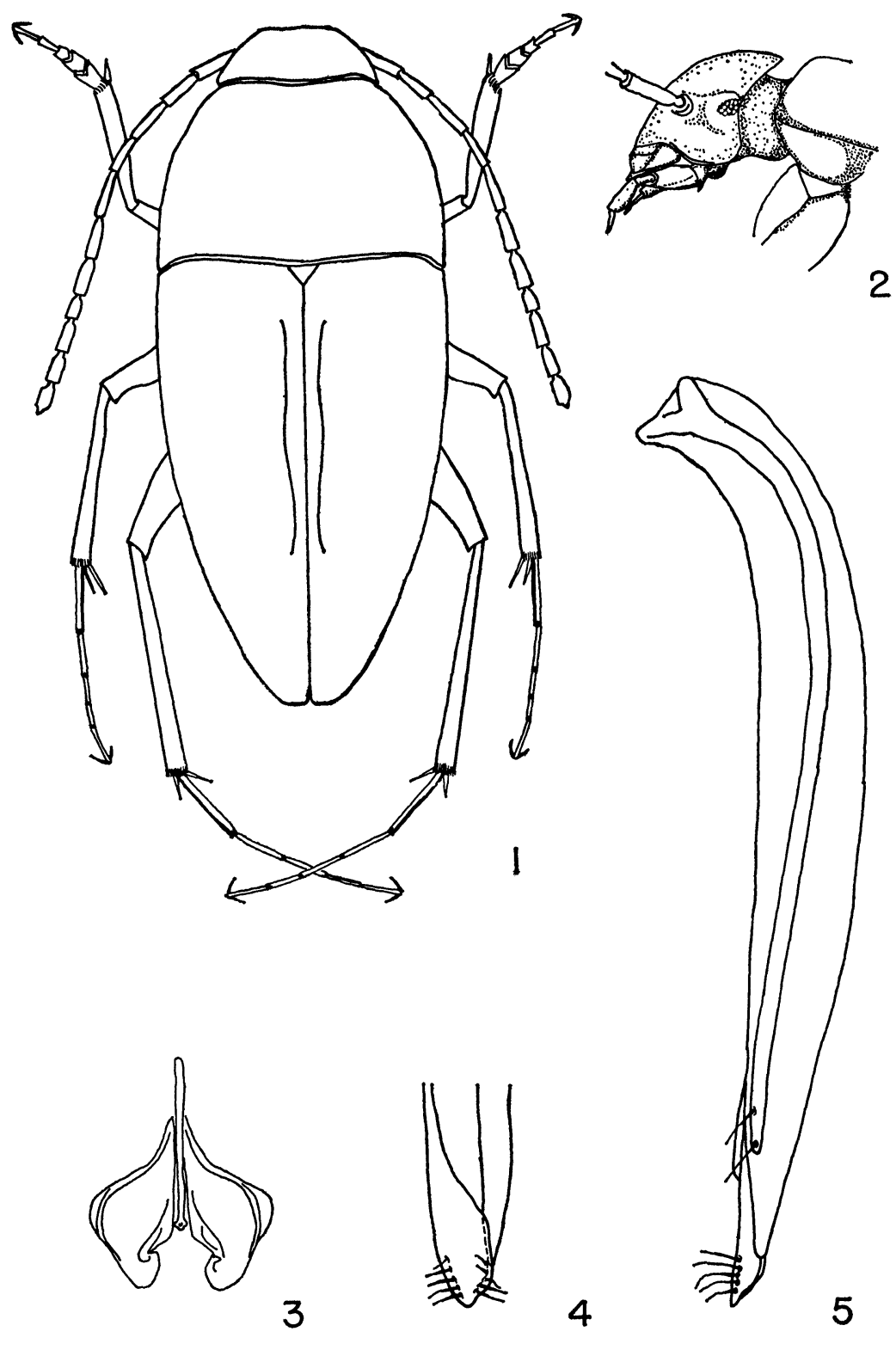

Peck - Catopid Beetle 
Discussion. A comparative indication of the degree of cave adaptation possessed by $P$. troglomexicanus is given in Table I. The species is compared to an epigean, a troglophilic, and a troglobitic species from the eastern United States: P. consobrinus Leconte is found in eastern North America from Massachusetts to Iowa southward to Florida and eastern Texas. It is a winged, eyed, forest litter-inhabiting species. $P$. cavernicola Schwarz is a winged, largeeyed species known only from caves in a large arc from Florida to the Ozarks and eastern Iowa down to central Texas and into northern Nuevo Leon, Mexico. Though it can fly, it is apparently limited to caves by ecological factors. $P$. loedingi Hatch is a wingless species whose eyes are reduced to small, unpigmented, vaguely faceted areolae. It occurs limited to caves in the vicinity of Huntsville, Alabama.

As the table shows, in this series of species, in a comparison of the ratios of length to width of three selected appendage segments the numerical value increases as the species becomes more cave limited. $P$. loedingi possesses a more slender hind tibia, but troglomexicanus possesses a more slender third antennal segment and first segment of the hind tarsus. These differences may or may not prove to be significant when the range of variation is learned for each species.

\begin{tabular}{|c|c|c|c|c|}
\hline & $\mathrm{L} / \mathrm{W}$ & $\mathrm{L} / \mathrm{W}$ & $\mathrm{L} / \mathrm{W}$ & EW/HW \\
\hline & FSHTar & HTib & TAS & \\
\hline $\begin{array}{l}P . \text { consobrinus } \\
\text { Jefferson Co., Mo. }\end{array}$ & 4.5 & 8.0 & 1.25 & .670 \\
\hline $\begin{array}{l}\text { P. cavernicola } \\
\text { Marvel Cave, Mo. }\end{array}$ & 7.8 & 9.7 & 2.60 & .650 \\
\hline $\begin{array}{l}\text { P. loedingi } \\
\text { Shelta Cave, Ala. }\end{array}$ & 9.0 & 12.0 & 3.60 & .290 \\
\hline P. troglomexicanus & 10.0 & 10.7 & 4.50 & .370 \\
\hline
\end{tabular}

Table 1. Ratios of measurements of a specimen of four species of North American Ptomaphagus, showing comparative lengths of appendage sections and the size of the eye. Abbreviations: $\mathrm{EW} / \mathrm{HW}$, horizontal eye width divided by width of head between edge of antennal socket and lateral edge of head; FSHTar, first segment of hind tarsus; HTib, hind tibia; $L / W$, length divided by maximum width; and TAS, third antennal segment.

Explanation of Plate 4

Figures 1-5. Holotype male of Ptomaphagus troglomexicanus, from Cueva de la Perra, Tamaulipas, Mexico. Fig. 1, dorsal view of adult, hairs and strigae omitted. Fig. 2, side view of head showing small pigmentless eye. Fig. 3, ventral surface of genital segment. Fig. 4, ventral view of tip of aedeagus. Fig. 5, lateral view of aedeagus. 
However, the similarities suggest a comparable level of cave adaptation for the two species.

The last column of the table presents the data on the lateral width of the eye compared to the lateral width of the head between the antenna and the vertical carina forming the side of the head. The eye of troglomexicanus is significantly larger than of loedingi.

Appendage elongation may be a positive adaptive response to compensate for the loss of visual environmental information. With longer appendages covered with more sensory hairs, a beetle could receive information from a greater volume of its environment. Vandel (1965) has reviewed this argument, citing organisms which both favor and refute it. He notes that since many groups of cave animals do not possess appreciably lengthened appendages, the argument is inadequately supported. However, we should not assume that all taxa, after adaptation, will exhibit the same degree of morphologic specialization. A situation may be adaptively solved by more than one answer. Various physiological, behavioral, or other characteristics may be of greater significance in some taxa not showing appendage elongation. Laboratory experimentation on the beetles' sensory physiology may possibly tell us if the tendency towards appendage elongation is really the result of a positive selection for greater sensory capability.

In a totally dark environment, eyes would seem to be of no selective value. With relaxed selection, loss of the organ system will follow the accumulation of degenerative mutations. Sadóglu (1967) has investigated this phenomenon in the Mexican cave fish Anoptichthys. The eyes of $P$. troglomexicanus, when compared to $P$. loedingi, are not reduced in proportion to the degree of lengthening of the appendages. This undoubtedly reflects the expected discordant selective forces acting in the two sets of organ systems. The gradual loss of eyes may be considered as a selectively neutral byproduct of the genetic reorganization experienced during adaptation to a cave environment (Barr 1967).

Compared to temperate areas, very few troglobitic beetles are known from tropical areas. The present view on the origin of troglobitic beetles is that they evolved from epigean ancestors living in the areas of the caves during the cold-wet glacial periods. The entry into caves was brought about by changing climatic conditions; the unsuitable warm-dry periods of the interglacials (Barr I968, Jeannel 1949). The interglacial epigean environment became unfavorable for cold and moisture demanding species. They were 
forced into caves to find these conditions, and the populations were isolated by extinctions of the local epigean species members. This phenomenon also seems to be responsible for the evolution of most of the few tropical troglobitic beetles.

Perhaps the best faunally explored tropical caves are in the Congo Republic of Africa. A number of beetles live in these caves, but very few display any degree of cave adaptation (Leleup 1956). Most troglobites of temperate caves are derived from groups which are extensively humus and moss inhabitants in montane forests. The high forests of the central African mountains support a rich humus-inhabiting beetle fauna. The lack of African cave beetles may then be explained by the possibility that Pleistocene climatic alterations were not severe enough in the central African mountains to sufficiently depress the montane forest zones. The forests and their humus faunas were not able to reach into the lowland Congo cave region. The preadapted humus fauna never had access to the caves (Leleup 1956).

The possible climatic changes during the Pleistocene in Mexico are poorly documented. However, since glacial moraines exist some $2000 \mathrm{~m}$ below the present glaciers of some of the highest Mexican mountains, we may assume that the montane forests of the past enjoyed conditions that were cooler and more moist than today. It is significant that in the known Mexican cave carabid beetle fauna, reviewed by Barr (1966b), the majority of the troglobites are from caves at high altitudes. It is similarly significant that $P$. troglomexicanus, the first described Mexican troglobitic catopid, occurs in a cave at an elevation of 2160 meters. All other Mexican cave Ptomaphagus that I have seen (six undescribed species from I2 caves) are from lower elevation caves and with one exception do not display modifications for cave life. These latter species may not display cave adaptations because they may be only recently isolated in caves by extinctions or emigrations of the surface populations, or they may be species that find caves to be as suitable a habitat as nearby epigean environments. The suggested moss or humus-inhabiting epigean species, or its descendant, ancestral to $P$. troglomexicanus, may still exist at higher elevations. These possibilities can be answered only by further collecting in the rich and varied environments found in Mexico.

Barr, Thomas C., Jr.

\section{Literature Cited}

1963. Studies on the cavernicole Ptomaphagus of the United States (Coleoptera: Catopidae). Psyche, 70: 50-58. 
1966a. New species of Mexisphodrus from Mexican caves (Coleoptera: Carabidae). Psyche, 73: 112-115.

1966b. Mexican cave beetles of the family Carabidae. Association for Mexican Cave Studies, Austin, Texas, Newsletter, 2: 182-185.

1967. Observations on the ecology of caves. American Naturalist, 101 : 475-492.

1968. Ecological studies in the Mammoth Cave system of Kentucky. I: The biota. Intern. J. Speleology, 3 : 147-204.

Bolivar y Peltain, C., and J. Hendrichs

1964. Agoninos cavernicolas nuevos del genero Rhadine de Nuevo Leon, Coahuila, y San Luis Potosi (México) (Col., Carab.). Ciencia

JEANNel, RenÉ (México), 23 : 5-16.

1936. Monographie des Catopidae. Mem. Mus. Nat. Hist. Nat., Paris, nouv. sér., 1, $433 \mathrm{pp}$.

1949. Les coléoptères cavernicoles de la région des Appalaches. Étudie systematique. Notes Biospeologique, 4. Publ. Mus. Nat. Hist. Nat., Paris, 12: 37-115.

LeLEuP, N.

1956. La faune cavernicole de Congo Belge et considerations sur les Coléoptères reliques d'Afrique intertropicale. Ann. Mus. Royal du Congo Belge, Tervuren (Belgique), Ser. in $-8^{\circ}$, Sci. Zool, 46: $170 \mathrm{pp}$.

SAdō̄LU, Perihan

1967. The selective value of eye and pigment loss in Mexican cave fish. Evolution, 21 : 541-549.

SZYMCZAKOWSKI, WACLAW

1961. Espèces néotropicales nouvelles ou peu connues de la famille VANDEL, A. Catopidae (Coleoptera). Bull. Entomol. de Pologne, 31: 139-163.

1965. Biospeleology, the biology of cavernicolous animals. Pergamon Press: New York. 524 pp. 

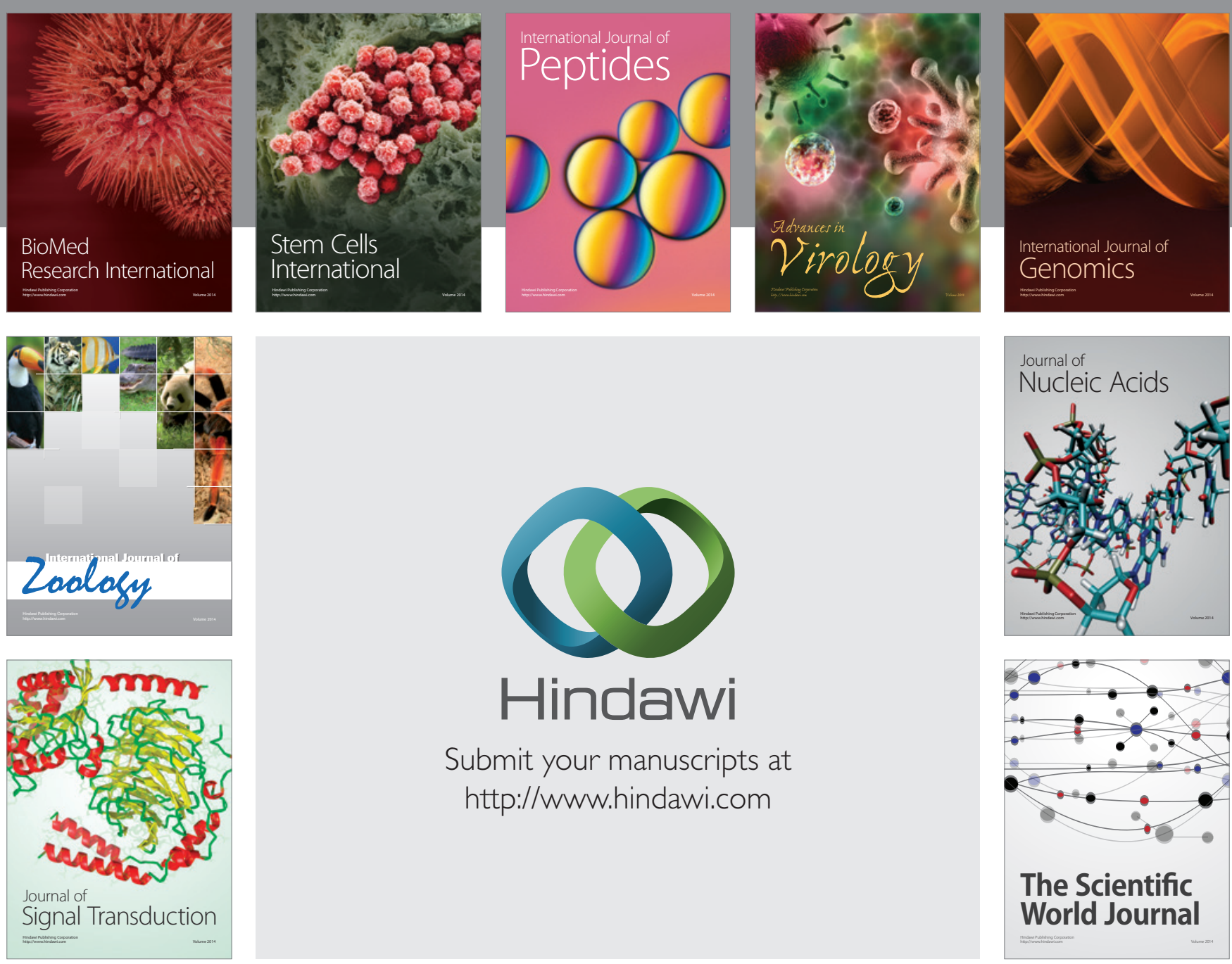

Submit your manuscripts at

http://www.hindawi.com
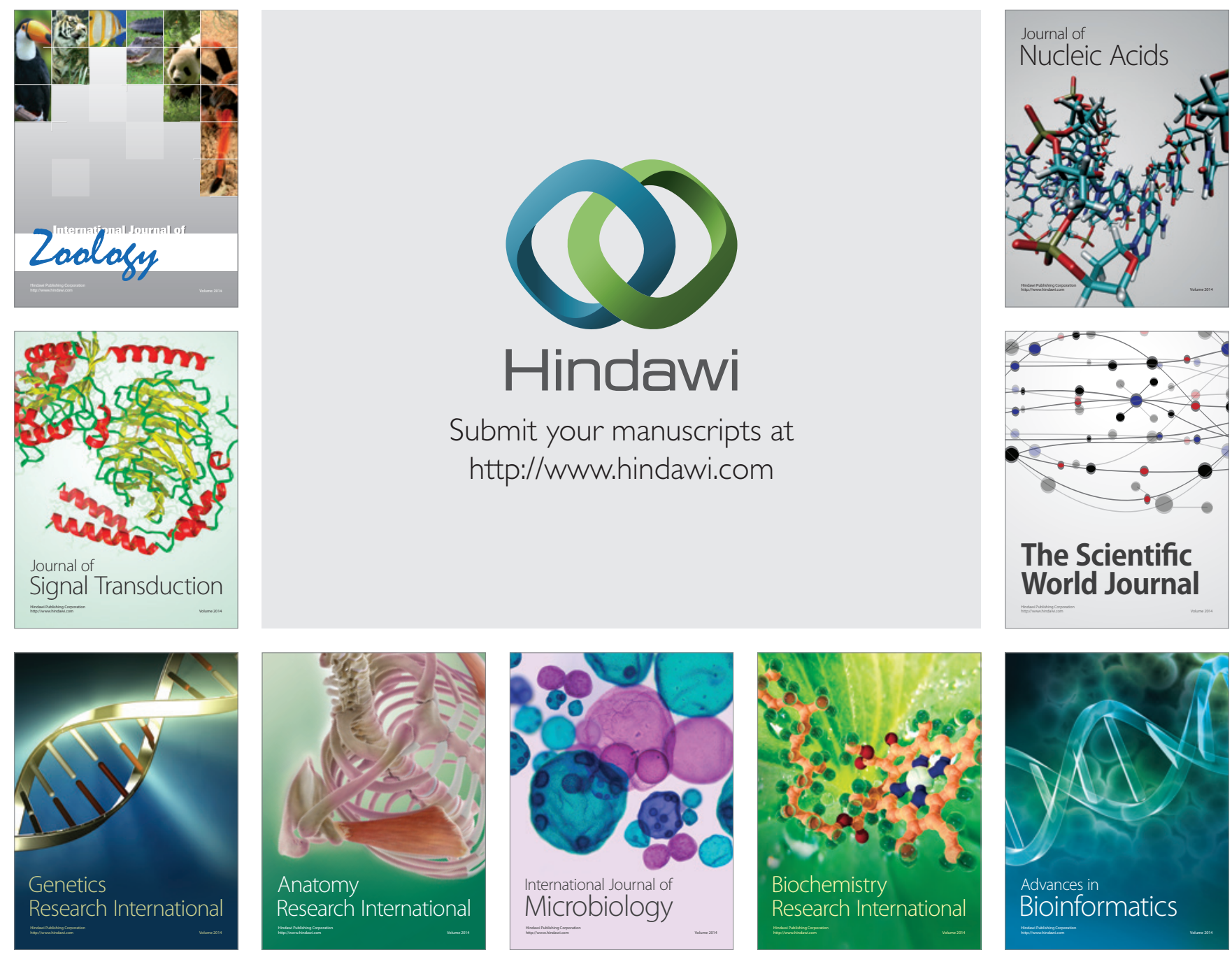

The Scientific World Journal
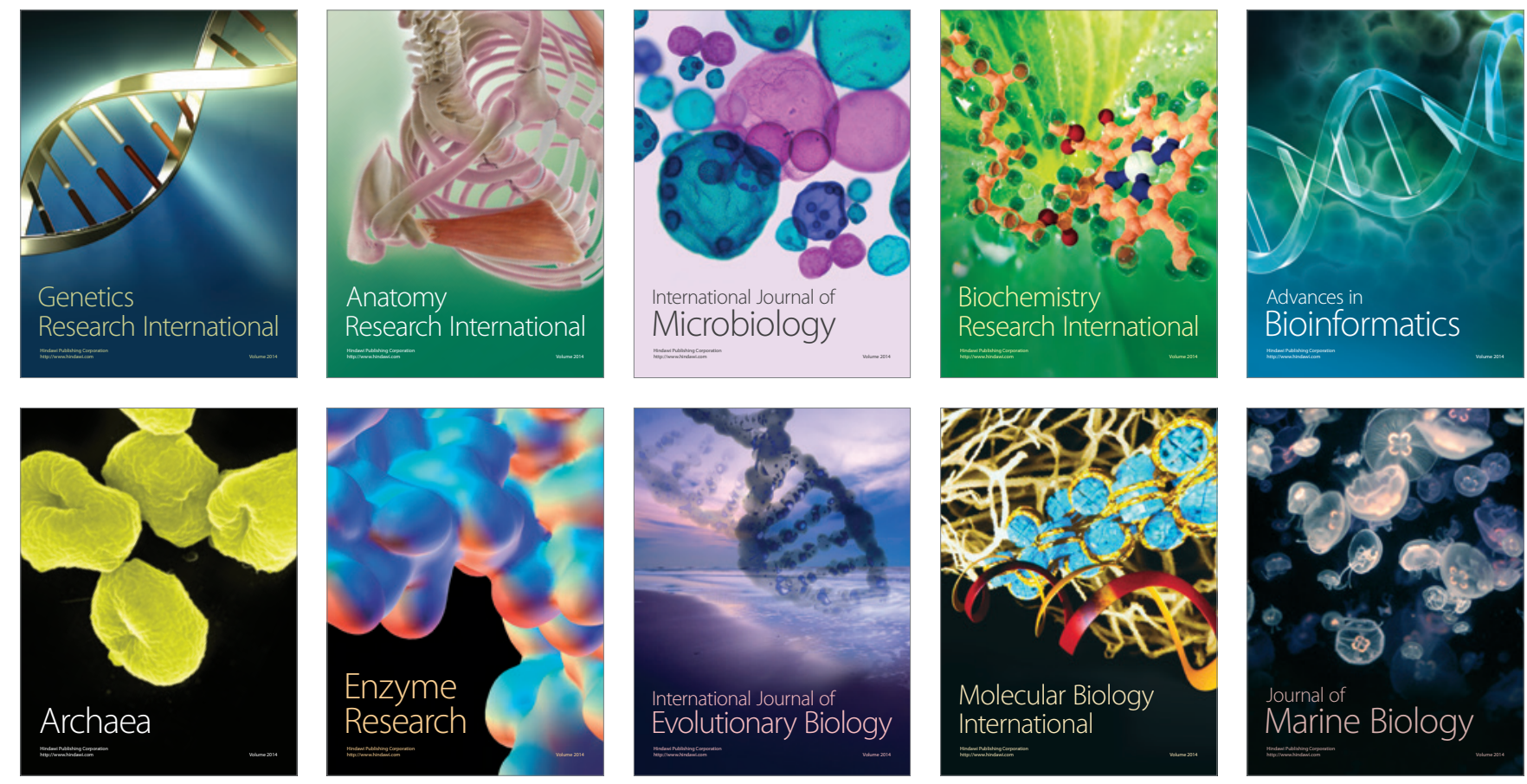